ARTICLE

\title{
The Representation of Motherhood in Post-Socialist Chinese Cinema
}

\author{
HUILI HAO, University of Sussex
}

\begin{abstract}
Critics agree that the mother figure has consistently played an important role in Chinese cinema. But this topic has rarely been addressed. This paper will explore what others mother figures can be found in Chinese cinema from 1990 onwards besides the mainstream representation of motherhood that carries both the national modernization and the women's traditional merits. In this paper, I shall investigate three paradigms of the representation of motherhood in Chinese films since 1990s. The first paradigm is the Exemplary Mother, which seeks to construct the main discourse of motherhood through complying with the main-stream ideology. The second paradigm is the Transgressive Mother, which resists the myth of the good mother. The third paradigm the Consistent Mother in Chinese feminist films, which concerns the mother's subjectivity and experience, emphasizing the strong bonding between mother and daughter, and normally giving them a positive future.
\end{abstract}

\section{KEYWORDS}

Representation; motherhood; Chinese film

\section{Introduction}

Post-socialist China has seen economic and political changes that have affected all areas of Chinese society, including discourses around gender. With regards to motherhood, the discourse has become more complicated than during the Mao era. Heterodox discourses on motherhood, which had almost disappeared from the representational system (including film) prior to 1979, has now returned.

This paper studies the representation of motherhood in the films of post-socialist China in relation to the multiple discourses on motherhood during this same period, followed by a discussion of the relationship between these discourses, especially their relationship with the representation of motherhood in films. Therefore, discourse analysis and textual analysis are the main approaches in this research. 


\section{Re-emphasis of motherhood and other roles of women}

The time after 1978 has been officially named the 'Reform and opening-up period' by the Chinese government. China at this stage has been transforming, according to the official term, from socialism to 'socialism with Chinese characteristics'. In academic research of the West, however, this stage is called the post-socialist or post-Mao era. Paul Pickowicz believes that post-socialism is based on socialism and can be used to explain the Chinese culture after the Mao era. He explains that this period sees a society, which has traces of the traditional socialist culture, and the elements of modernism and postmodernism (Zhang 2007, p.50).

Based on this perspective of the complexity of the Chinese culture of the post-socialist period, the gender discourse also presents a multiplicity of views. It includes the Maoera's official discourse of 'men and women are the same'; the return of the traditional roles of women intermixed with the popular culture in the current market economy; and the overturn of the former gender discourses in women's literature and other approaches (Thakur 1997, Dai 1999, Wu 2000). There is also an overlap in all these discourses, in that they all share the principle of an essentialised femininity. These gender discourses provide a reference framework for discussing motherhood and to look at what motherhood is during the post-socialist era.

At the stage of the post-socialist period, a gender discourse about traditional women's roles reemerged. Women were encouraged to be virtuous wives and good mothers. Motherhood was regarded as women's nature. But women did not think they would become an ideal wife through blind obedience to her husband any more (Honig and Hershatter 1988, p.173). Furthermore, in the post-socialist China context, being a good mother demands from women not only bringing up physically healthy children, but also mastering the skills that would enable her to sensitively guide the psychological development of her child (Honig and Hershatter 1988,, p.180).

The state, however, gets involved with this process. The reports of the congress of All China Women's Federation, from 1978 until now, put substantially more focus on motherhood particularly. The slogan on motherhood in post-socialist China is 'Fostering children for our country in a scientific way and with morality' (weiguo jiaozi, kexue yu er, yide yu er). The official discourse asks women to 'painstakingly nurture the offspring'.

Parents are the first teacher of their children; family is the natural school for educating the children; the sound and healthy growth of children will not be possible without parents' education and family influence.

(Jiang Zemin, 1998)

Here, the state ideology expects or demands parents to nurture their children according to the state's education principle and target. As Ann Anagnost (1995) has argued: 
The policy and the popular consciousness it has engendered are concerned with the quality, rather than simply the modern nation. Birth planning pursues in yet another way the phantasm of modernity. It hopes to produce a physically and intellectually capable population, one that will be robust in the face of competition.

(Quoted in Rofel 1999, p.246)

For three decades, this official discourse about motherhood has been continuing; as the children directly influence the future of the nation and the prospects of the country, the duty of women as mothers is an important topic. Such discourse reflects the state power's control and regulation of maternal identity, which increases the burden of women as mother.

The trend of naturalization in gender relations does not mean that the 'equal rights between men and women' from the Mao era disappear. 'The Chinese Communist Party has constantly expressed support for female liberation, this support has been conditional on women's specific interest not conflicting with the overall interests of the Party'(Croll 1978, Thakur 1997, p.60 ) The All China Women's Federation adopts the 'men and women are equal' in their women work: calling for the women (including mothers) to regard the realization of 'the four modernizations' - the central task of the party and the country - as the core of women work; requesting women to take equal part in this task so as to realize their value of life.

Furthermore, from 1949 in Mao era, women have been encouraged to take part in socialist work for equality, thereby giving women more freedom and liberation. Therefore during the economic reform more women worked in the society and they are reluctant to return to their families (despite the call by some people to 'let women go back into home') and undertake the traditional role as 'a virtuous wife and good mother'.

Hence under the economic development conditions women still undertake the dual burdens, which are, however, slightly different from those in the 1950s. In that period, the society did not significantly advocate the natural role of women, including motherhood. For instance, in relation to the attitude of women towards motherhood between 1949 and 1979, Rofel (1999) found in her investigations that women back then did not care about motherhood and thus did not feel guilty for failing to fulfill their motherhood (p.229).

Nevertheless, in the reform era, women take part in social work on the one hand and, on the other hand, have to be pressured by the discourse that emphasized femininity, including motherhood. Therefore, the dual pressures faced by women are probably even heavier that those in the Mao era. With regard to this problem, All China Women's Federation have introduced its countermeasure, for example, the National Women's Congress promoted that 'male and female members of the family share the housework reasonably and take effective measures to reduce the burden of 
housework' and advocated socialization of housework (All China Women's Federation, 1978; 1983). Yet just as what most Western feminists believe, all these have failed to overthrow the orthodoxy discourse of gender relations in China.

The official ideology advocates that women/mother plays an active role in the national modernization. Women should adhere to the traditional merits of nurturing children, and try to build up and maintain good family traditions. However, different voices on motherhood in various Chinese representational systems are challenging the official voices on motherhood through women's own experience of motherhood, and women's writing. For example, a female protagonist in a prime time television drama Double Sided Tape (Shuang mian jiao) reminds her colleague who is hesitating to have a child or not:

You must not give birth to a child because of the filial piety; also you must not give birth in order to modify the conjugal relationship. If you do like that, it is definitely irresponsible for the child. Giving birth completely is your own matter. You should bear a child, after you have ample psychological preparation and when you are really eager to have one. Otherwise it would drive a healthy woman into madness.

The focus of the next section is the representation of motherhood in the work of some Chinese female writers from the post-socialist period and to find out how the orthodoxy discourse of motherhood have been challenged. Their rewriting of motherhood points to the conception that motherhood should be a free choice, not a woman's destiny.

\section{Rewriting motherhood in women's literature}

The literature on motherhood since the 1980s is still dominated by the stories of good mothers but there are some heterodox voices, wherein the heroines in novels can have the 'consciousness of female self vis-à-vis a motherhood which is not a self-chosen engagement but an imposition' (Jiang 2005). In the article Against Myth and History: A New Writing of Motherhood in Contemporary Chinese Women's Literature, the author Jiang Haixin concludes that women writers since the 1980s began to expose the discourse of good motherhood as a myth. She argues that 'the earliest feminist liberation of women from the conceived maternity can be read in Zhang Xinxin's On the Same Horizon (Zai tongyi dipingxian shang, 1981) and Zhang Jie's The Ark (Fang zhou, 1982). Both heroines put their prioritization of work and self-fulfillment over maternity. However, it is in Zhang Kangkang's novel The Invisible Companion (Yinxing banlü, 1986) that the maternal nature is further rejected. Xiaoxiao, the heroine of the novel, unexpectedly becomes pregnant. When she gives birth to a baby boy, the narrative relates: 
Nothing was like what is described in stories - the young mother is filled with feelings of happiness at her first sight of the baby. In this room, on the bare earthen bed, she was filled with a strange sense of alienation. She felt life was somewhat absurd to her.

(Quoted in Zhang Kangkang's novel The Invisible Companion 1995, p.179)

Women writings in the 1990s carry on the topic of questioning the idealization of mother, on the other hand, 'patriarchal mother', the figure who forgets her essential opposition to patriarchy and identifies with it, constitutes another kind of resistance to the myth of good mother; Xu Kun's Nüwa (1993) can be seen as the typical example in this paradigm.

As mentioned above, there were multiple motherhood discourses in the post-socialist China, including the resurgence of traditional female roles, the official discourse which demanded women to both contribute to the four modernizations and focus on their motherhood, and discourses seeking to radically question all elements of a traditional and socialist orthodoxy (Thakur 1997, p.64). All these suggest their simultaneous existence and the interaction amongst them. The regression to womanliness re-emphasizing the identity of women as women, including motherhood, is the common point where these discourses overlap, but there is still tension between them and this was represented in films. A later section will discuss films that dealt with motherhood discourses and how these discourses reconsolidated their own ideology about motherhood through the contest of power and the re-presentation in films.

\section{The background of the post-socialist Chinese cinema}

Compared to the ultra-left trend of thought in the cultural sphere during the Cultural Revolution, the Fourth National Congress of Writers and Artists in November of 1979 provided the artists with the relatively relaxed mood and autonomy. In the same year, the slogan which had governed them since the Yan'an Forum in 1942, 'let literature and the arts serve politics' was amended to 'let literature and the arts serve the people and socialism', and filmmakers were able to castigate the brutality of the Cultural Revolution by exploring previously taboo or sensitive subjects and genres such as political persecution, female sexuality and martial arts. Therefore, multiple trends came into being, with the liberation of ideology and the installation of humanism in culture (Yin Hong and Ling Yan 2002; Zhang 2004, p.226-240; Berry 2004, p.92).

These trends continued since then, as Ann Wedell- Wedellsborg (1999) argues, the culture scene in 1990s China was more diversified, and it is the commercial, rather than the political, factors that are determining the majority of what is going be published and produced. Guidelines from party leaders are no longer the main agents of cultural changes (p.224-5). The Chinese scholars, such as Yinhong, Ling Yan and Zhang Yingjin have the same opinion about the general trend of Chinese cinema in this period, that is, with the acceleration of the market mechanisms since the late 1980 s, the Chinese cinema has been transferred from the apparatus of political propaganda to the property of cultural industry (Yin and Ling 2002, Zhang 2004). But 
they also assert that in the 1990s, the CCP (Chinese Communist Party) investment in leitmotif films has constituted an intensified, prolonged ideological drive to instill patriotism and nationalism in the population, especially the younger generation (Yin and Ling 2002, Zhang 2004). But Leitmotif films are not a 'pedagogy of arts', more strategies have been adopted to reinstall a correct political ideology and nationalistic pride in the population. (Yin and Ling 2002, Zhang 2004, p.154; p.240).

Zhang Yingjin, divided the post-socialist Chinese cinema since the early 1990s into three types: leitmotif film, commercial/entertainment film and art film. Leitmotif film in Chinese context refers to the film with state-subsidized, propagandist in nature. In recent years, its definition has been becoming more flexible. Nevertheless, most of films are not pure of each genre, rather than mixed different elements into each other (Zhang2004, 240). The selected mother's films in this paper bore this mixed characteristic.

\section{Representation of motherhood in films}

The mother figure is regarded as the only figure which is eulogized and narrated, and has consistently served as a visual trope in Chinese cinema (Dai 1999, Cui 2003). This section will explore what others mother figures can be found in Chinese cinema from 1990 onwards besides the mainstream representation of motherhood that carries both the national modernization and the women's traditional merits.

Taking a look back to the films from 1949 to 1979, in the socialist Chinese cinema the mother is represented as the revolutionary mother or the ideologically backward mother. The maternal motherhood on screen was almost rejected, such as the image of Jiang Jie, the female protagonist in Live Forever in the Flame (Lie huo zhong yong sheng, 1964, dir: Shui hua), although she is also a mother the film has intentionally blurred her maternal identity. A similar situation takes places with Mother Guo in Locust Tree Village (huaishuzhuang, 1962, dir: Wang Ping).

Post-socialist Chinese films altered their course from the singular political mode of ideology to the pluralistic mode. The representation of motherhood becomes diverse in this period, although the official ideology still advocates the myth of motherhood. The films show varied and complex views on motherhood, even though the films carry the strong institutional discourse on motherhood, there are also films which represent more diverse and individualistic discourses on motherhood, including feminist thoughts in recent years in representation and in society.

I shall investigate three paradigms of representation of motherhood in the 1990s Chinese films. They are: the Exemplary Mother; the Transgressive Mother and the Resistant Mother.

\section{The Exemplary Mother paradigm}

The Exemplary Mother or good mother paradigm represents a self-sacrificing mother, who is advocated by leitmotivs film (Zhuxuanlü), which constructs the discourse of motherhood by means of complying with the mainstream ideology of motherhood. 
The good mother paradigm is not unique to Chinese screens in the 1990s; it has prevailed since the beginning of the 20th century, when movie production started in China. The 'essence' of good mother in Chinese film history has not changed fundamentally.

Laura Mulvey writes that the feminists engaged in critical reading of cinema whether as film critic, as film-maker, or as audience member - should take the stance of 'passionate detachment' (Thornham 1997, p.ix). In analyzing the weepy films of the exemplary mother paradigm, the stance of 'passionate detachment' can reveal what ideology on motherhood reinforces in the representation of the self-sacrificing mother in film. What strategies do film-makers use to make the audience (mainly a female audience) identify with the mothers on screen? And how do film-makers reach a compromise between the demands of the market and the demands of ideology?

Taking the film Jiu xiang (1995, dir: Sun Sha) as an example of the good mother paradigm. It talks about how a widowed mother called Jiu Xiang sacrifices herself and suffers many hardships to bring up five children and sends all of them to university. In traditional Chinese culture, the basic requirements for a 'good mother are fertility and raising children, assisting her husband and teaching her children, showing respect to the old and taking good care of the young, being frugal and good at running her home' (Du, 2003).

Jiu Xiang as a mother satisfies all of the conditions. She has five children (four sons and a daughter), which satisfies the first condition - fertility. The wife next door only has two daughters so Jiu Xiang's four sons always make the neighbour's husband look on in admiration. The issue of preferring a boy becomes exposed through the efforts of the couple next door who are trying to have a boy. In the film, it is not the main issue, so is tackled in a comedic way; for example, when they fail to have a boy, the father makes a joke that he is going to teach his daughter to become the first generation of female butcher in China.

In the films about the good mother, the family is usually fatherless and the mother is usually in very poor health. This strategy allows the mother to surpass unimaginable difficulty by herself, and therefore become a good mother. This type of film about motherhood usually frankly worships the greatness of motherhood. In Jiu Xiang, when the mother Jiu Xiang falls sick after raising her children one after another, the doctor - a character symbolising authority in the patriarchal society - informs her children with a solemn expression and a sad tone: 'There will never be a mother like yours.' He continues to explain that Jiu Xiang is in very poor health and it is miraculous that she has held on so long. Again, the film imposes its ideology on the mother: however weak she is, she has to fulfill her role as mother. The sacred love of a mother has outlasted her health condition. In this way, the film delivers to the audience a myth about motherhood.

The conflict between motherhood and sexual desire has always been an issue both in western culture and eastern culture. From the purity of holy Mary to the good qualities of Sophia in Rousseau's Emile (1672) and to the worship of such qualities as 'piety, purity, domesticity and obedience' in 'The Cult of True Womanhood' (Kaplan 1992, p.17-26). Similarly, traditional Chinese culture attaches great importance to chastity. The good mother should be de-erotic, which is another strategy the film-maker uses to 
eulogize a mother. In films, mothers are usually plainly dressed and wear no makeup. Their image is dignified and un-coquettish, their action restrained and their desire suppressed.

After the death of the husband, a woman is obliged to keep her chastity. The mother in Jiu Xiang is an example of a chaste woman of the three obediences, which means obedience to father before marriage, to husband after marriage, and to son after the husband's death. After the death of her husband, she has to raise five children all by herself. Life is tough, and a man, Lao Guan always helps her. The two fall in love, yet to Lao Guan's proposal of marriage, the mother Jiu Xiang replies that her husband had not been gone for three years - a traditional Chinese convention, but still haunting the culture-how could she marry again? This is keeping chastity for the dead husband.

In another scene, after her children have fallen asleep, the mother goes out for a date with Lao Guan. The date here is different from that in Western films such as Unfaithful (2002, dir: Adrian lyne) and The Piano (1993, dir: Jane Campion), wherein mothers release their suppressed sexual desire. Here the film carefully and conservatively handles the sexuality of the mother with Lao Guan merely hugging Jiu Xiang. There is no kissing, let alone any sexual intercourse. Even so, the eldest son, who represents the father's right and authority, leads the sister and brothers to 'promptly' prevent the further development of the mother's desire.

The repeated obstructions and interruptions from her children have prompted the mother to make the decision: 'I can't marry you. I have the children.' This is keeping chastity for her children, which in effect means that the mother is still placed in a proper position as dictated by the patriarchal system.

Films that fall within this paradigm, however, no longer simply act as a political microphone; they now incorporate some entertainment elements which intend to naturalize the ideological 'interpellation'. In order to win the audience identification, in 1990s Chinese films the director has to compromise between the market and the official ideology.

One of the strategies in the film is how to solve the conflict between motherhood and sexuality. On the one hand, the film shows the mother's desire to let the audience enjoy 'visual pleasure'; on the other hand, the mother's desire is always under control. However, her desire is maneuvered into the film through representing the mother always carefully keeping the hairpin given by her suitor.

Therefore, this film, shot in the mid-1990s, abides by the discourse of motherhood in the mainstream ideology. Meanwhile it takes into consideration the marketing and the potential audience, effectively realizing the 'suture' between ideology and audience. This exemplary mother paradigm persuades the audience (the female audience, in particular) to identify with the painstaking mother and to believe that such a sacrifice is absolutely worthwhile through her children's successes in society.

In recent years, critics have paid attention to the intersections of gender and nation that occur in cinematic representation, 'In the history of Chinese cinema, gender and nation have often served as narrative subjects and visual tropes in Chinese cinema'. (Cui 2003, p.xi); '...analysts of gender and nation have tended to argue that 
motherhood is the primary role that links women and the nation.'(Berry et al 2006, p.109). From the same point of view, Jiu Xiang and many more films produced since 1990 fall within the category of the Exemplary mother paradigm, they can be read as the national allegory a few of them are listed: Do not cry, mum (Bieku Mama, 1990, dir: Zhang Yuqiang); The Stepmother (Jimu, 1992, dir: Sun Daolin); Breaking the Silence (Piaoliang Mama, 1999, dir: Sun Zhou); To be a Mother (Wei ren zhi mu, 2000, dir:Shi Xuemei); Judge Mama (Faguan Mama, 2001, dir Mu Deyuan); Running for Son (Duozi, 2003, dir: Ning Jingwu); Do not leave me (Buyao Likai Wo, 2003, dir:Wang Guoxian); Cherries (Yingtao, 2006, dir: Zhang Jiabei); On-line Mum (Wangluo mama, 2008, dir:Zhou Yong).

Considering that the slogan of motherhood in current times is 'educating children for the nation, fostering children with morality', all of the mothers in the above films can be read as representative of Chinese women, and also can be read as the metaphor of the party and the nation. The poor but strong-minded mother conquers all hardships by sacrificing herself and brings up her children to be socially responsible. It signifies that the party or the nation lead all Chinese people to overcome misfortunes.

\section{The Transgressive Mother}

The second paradigm is the Transgressive Mother or bad mother paradigm. Films such as Ju Dou (Ju Dou, 1990, dir: Zhang Yimou \& Yang Fengliang) and Gentle Billow in Stagnant Water (Kuang, 1991, dir: Ling Zifeng) have representations of 'fallen mothers', which challenge the myth of the good mother in Chinese cinema.

The first characteristic of the 'fallen mother' is her transgression of morality, for example the mothers in Ju Dou and Gentle Billow in Stagnant Water (Kuang) who both have a sexual relationship with a man who is not their husband. Both of them, in the narrative challenge the conflict between motherhood and sexuality.

Many critics have analyzed $J u$ Dou from different perspectives, but its analysis from the point of view of motherhood has been neglected. At the beginning of the film, it is suggested that, as a woman, Ju Dou can not escape from the traditional destiny of women; to be a mother. Ju Dou does not have the freedom to choose her marriage. She was sold to Yang Jianshan, the owner of the dye factory, as the third wife in order to provide a family lineage. Her husband is an old, impotent and hostile man. He tortured his first two wives to death and now treats Ju Dou as slave labor in the day and abuses her in the evening for failing to give birth to a child. The film also mentions that his first two wives could not escape the traditional fate of women; they were tortured to death mainly because they could not give birth to a child. Ju Dou is represented as a rebellious woman who rejects the traditional conception of a virtuous wife and good mother.

Her resistance takes the form, first, of refusing to be a loyal wife. She gets pregnant with another man. This violates marital commitment. Second, the man she falls in love with, Tianqing, is her husband's adopted nephew, that is, in terms of the strict Chinese kinship system, Ju Dou is Tianqing's aunt. Therefore, their relationship signifies the transgression of the lineal relation prescribed by society. Third, Ju Dou does not hide the truth of her illegitimate son. She demystifies the purity of the 
discourse of motherhood by telling her husband 'I tell you clearly, Tianqing is his (Tian Bai) dad indeed'. Fourth, it is Ju Dou more than Tianqing who plays an initiate role in their relations. She seduces Tianqing after she finds out that he is peeking at her when she takes a wash. She transgresses the de-eroticised discourse of motherhood.

Ju Dou's strong sexuality is represented by the changing of the space where she and Tianqing have sex. At the beginning, the space of their relationship is in Tianqing's room. After her husband is paralysed in an accident, she and Tianqing disregard her husband's presence and enjoy their sexuality. Since her husband dies, Tianqing is not allowed to live in the same house as Ju Dou by the Yang clan. There is no space for them to have sex in the house. The space is reduced to only a corner of the house, where they can enjoy intimacy when the son is not at home. Thus, Ju Dou and Tianqing have to continue their love affair secretly in the wild and in the cellar.

The good mother is expected to look after her child carefully. The injury or loss of a child is a very common punishment for a bad mother in representation. As a mother, Ju Dou neglects her motherhood. When her son, Tianbai is a little baby, she often leaves him upstairs besides her paralysed but hostile husband, and goes to her lover's room. A few times, her husband wants to take revenge and kill the baby. Ju Dou is also punished by her son from when he is a little boy until his teenage years. Tianbai always fiercely stares at her after she spends time in Tianqing's room, or throws stones to the room, until he is old enough to kill Tianqing, his biological father. Tianbai starts talking later than normal children, which could be seen as a serious punishment to the mother.

Another issue related to motherhood is, as a wife of a paralyzed husband and later as a widowed mother, Ju Dou always worries that she will get pregnant again with Tianqing and she takes contraceptives which cause her a lot of pain. This context signifies the existence of motherhood as socially constructed, in other words, it is good and desirable for a woman to become a mother unless her pregnancy threatens the order established by the patriarchal society.

As a rebellious mother, Ju Dou's suicide at the end of the film is not triggered by her will to maintain chastity or morality, as in the Chinese representation system, female suicide is commonly for keeping chastity. It is rather emancipation from the traditional conception of morality, because it is the only moment when she is allowed to make a decision herself and take control of her own destiny (Kantorates 2008).

Another transgressive mother is in the film Gentle Billow in Stagnant Water (Kuang, 1991, dir: Ling Zifeng). The woman/mother seems always to be the owner of her fate. Her pragmatic attitude to life makes her not care about the conventional principles of woman/mother. The film uses her beauty to attract man's attention both inside and outside of the movie. The mother runs a grocery store and restaurant with her foolish husband. She works in public, not at home where the traditional mothers stay. Her customers are men who frequently come to her shop mainly to look at her. Outside, the film attracts the male audience by allowing them to gaze at her beautiful body; meanwhile it encourages the female audience to identify with the female protagonist when she conquers disasters one after another by her rebellious personality and her pragmatic view of life. 
In the representation of motherhood in films, mothers like this are always punished and forced back into the limit allowed by society. Yet the patriarchal rules adopted to discipline motherhood are attacked in this film, this film ends in a positive way for the mother, also it does not destroy the relationship between the mother and the son.

These two films are set in the past, $J u$ Dou is set in the 1930s and Gentle Billow in Stagnant Water is set at the beginning of the 20th Century. This strategy is used, on the one hand, to escape censorship. (Nevertheless, both of these films were banned in China for some years.) On the other hand, the audience can not get immediate identification through watching these past stories.

\section{The Resistant Mother paradigm}

Kaplan argues that motherhood has been repressed on all levels except that of romanticisation, and idealization' in western culture. Until the 1970s, 'Some women believe that by simply speaking our experiences and showing our everyday images we can bring about change'. Some women have started making films to explore the new motherhood (Kaplan 1983, p200-201). Since the mid-1980s, Western feminist theory and feminist film theory were introduced into the Chinese academy (Li 2006). These theories play a role implicitly or explicitly in the productions of Chinese female directors. In particular since the 21 st century, some of them seem to take the same strategy to construct the resistant motherhood.

For example, the film, He is My Father (Ta shi wo baba, 2005, dir: Gao Yunliang), mainly focuses on fatherhood, but the mother's voice is clearly heard. In this film, a father comes back after five years away working in shipping and he finds that his son can not recognize him and his wife has a suitor. He then wants to save his marriage, he says to his wife, 'I believe you and him (the suitor) are innocent'. Then the wife stops him and says:

Please do not use the phrase 'I believe...' to smother me. You believe I can run the home well; you believe I can look after our son; you believe that I am a living widow waiting for you to return home. What you say oppresses me too much...

The film, In the Heat of the Sun (Yangguang Canlan de Rizi, 1995, dir: Jiang Wen), represents a grumpy mother. She always shouts and beats her son. She scolds her son:

I am an educated person, I have never sworn at people. Now I am a housewife, but do you think I deserve this? All this is because I married your dad. You and your dad are the same, neither is good. You make me so mad... If you were a chicken, I would kill you.

Chinese women's films such as those from the female director Peng Xiaolian's movie Shanghai Woman (Jiazhuang mei ganjue, 2002) and Chen li's Duet (Lianggeren de balei, 2004) are constructing a different discourse of motherhood. Different from their male counterparts, they are concerned with the women's experience and the women's conflictive inner world, emphasizing the strong bonding between mother and daughter and normally giving them a positive future. 
In these movies, mothers are generally spoken by others, not speaking by themselves (Kaplan 1992, p.3). However, a remarkable characteristic of many of these films is that the daughter/granddaughter is the character who speaks about the mother's story. Taking Duet (Liang ge ren de ba lei,) as an example, directed by female director Chen Li. In this film, the screenwriter, director and the actors are all female. The story is an original idea from the screenwriter Su Ruijuan. She wants to depict a kind and optimistic mother to let the audience unload the burden of the traditional patriarchal culture in the family: as children, bringing honor to ancestors; as parents, raising children for the repayment from the children then they grow up. She hopes people live a simply but happy life (Bai Du,2007).

The story tells how a sterile woman adopts a girl soon after her husband dies in an accident when he works outside. Then both the mother and the daughter are thought of as unlucky sign. All the neighbours avoid having any connection with them, in the area where the story is narrated, men used to go out to work and women were left at home. All people in the town strongly suspect that any unlucky thing would bring disaster to their family, even to the whole area. The films talks about how, in this unpleasant situation, the mother sustains the bonding with her adopted daughter, and how the mother desires to teach her daughter ballet dancing. Both of them encourage each other to live a hard but happy life. As the name of the film, Duet, implies, the mother and the daughter are performing a beautiful dance together.

The union between mother and daughter is considered the most powerful by feminists. Kaplan argues that most maternal melodramas feature the relationship between mother and son, while most female films feature a mother-and-daughter relationship. (Kaplan 1992, p.165-170) Some Chinese female directors take this strategy to make the counter films.

In the Chinese people's view, giving birth to a son instead of a daughter is much more delightful for the mother and this can promote her position in the family, as girls were seen as burdens and temporary members of the natal family. But there are also optimistic sayings about giving birth to a girl: 'A daughter is like a wadded jacket for the mother.' This suggests that only a daughter can understand how the mother feels and a daughter is closest to her mother. Films representing the mother-daughter relationship have been on the rise in recent years.

When the girl in Duet is laughed at by her classmates because she was adopted, the mother does not attempt to cover up the fact, as stereotyped mothers in films would do. Instead, she tells daughter frankly: 'I adopted you because I can not give birth to a baby; if you were not born by me, wouldn't you want to be my daughter?'

After she tells her daughter the truth, the daughter goes out broadcasting firmly to the neighbors: I was adopted by my mum; I don't care what you say. So say whatever you want. Neither I nor mum will be afraid. None of you can take me away from my mum'. This bold announcement from the daughter seems not only intended for the neighbours, but also for the whole patriarchal society to show how strong the bonding between mother and daughter is.

The film not only presents the bonding between the mother and the daughter, but also 
highlights the alliance between the mother and other females. A neighborhood committee director, who is also a female, offers the mother a job; the old friend of the mother, Jin, has always been her colleague and bosom friend; and the neighbor Nanny Meng, attends to the heroine in times of difficulty, just as a mother would do.

This strong alliance between the mother and the other women is also shown in their addressing of the mother: neighbors call her Wife of Degui (Degui is the female protagonist's husband), which is a traditional way of addressing a married female in China by referring to her husband's name. As in western society, women used to be addressed as Mrs plus her husband's surname. Yet three people are the exception: Jin, the heroine's female friend, calls her by her nickname Sanzi (literally means the third child in her family); Nanny Meng, like a mother, addresses her as 'Girl' (Gui nü); and the daughter Xianxian (fairy girl) in the film calls her Xiannü mama (fairy mum). In this way, the two become beautiful 'fairy' in the eyes of each other.

Here is the list of some films that can be categorized into the paradigm of the resistant mother. They are made by female directors and/or screenwriters: Gone is the One who held me dearest (Shiejieshang zuiteng wode nageren zoule, 2002, dir/Screen writer: Ma Xiaoying);Electronic Shadow (Dianying Wangshi, 2004, dir:Xiao jiang); Duet (Lianggeren de balei, 2004, dir: Chen Li; screen writer: Su Ruijuan); Shanghai Woman (Jia zhuang mei gan jue, 2002, dir/screen writer: Peng Xiaolian)...

\section{Conclusion}

All in all, since the 1980s, socio-economic and political changes in China have been dramatic and rapid, directly impacting on both the discourse of motherhood and the representation of motherhood in representational system, including films.

Mother has developed from devoting herself to the country and to the Party, to sacrificing herself for the kids and then, to a certain level, to have her own subjectivity. We need a shift from the perpetuation of the good mother discourse into representing the contradictions, ambivalences and complexities of motherhood. 'Feminist art has begun to focus on the Mother's experience of ambivalence and contradictory demands' (Gledhill, Christine, 1990, 135). We need more of these type of movies 'to counteract the limited traditional Mother paradigms that patriarchy has for so long kept intact' (Gledhill, Christine, 1990, 135).

\section{References}

Bai Du (2007), About the Film Duet (Lianggeren de bailei), http://baike.baidu.com/view (Accessed 2 February 2007).

Barlow, Tani (2004), The questions of women in Chinese feminism. Duke University Press.

Berry, Chris \& Farquhar, Mary (2006), China On Screen: Cinema and Nation. Columbia University Press. 
Berry, Chris (2004), Postsocialist Cinema in Post-Mao China: The cultural revolution after the Cultural Revolution. New York and London: Routledge.

Croll, Elisabeth (1978), Feminism and Socialism in China. London, Henley and Boston: Routledge.

Cui Shuiqin (2003), Women through the Lens: Gender and Nation in a Century of Chinese Cinema, Honolulu: University of Haiwaii Press.

Dai Jinhua (1999), Looking from a slanted tower: Chinese film culture, 1978-1998 (Xieta liaowang:zhongguo dianying wenhua,1978-1998), Taipei:Yuanliu.

Du Fangqin (2003), Virtuous Mother and Dutiful Son: the construction of Motherhood and Practice, Chinese Literature and History, No.9. (Muxian zixiao: mu dao wenhua de lishi jiangou yu shijian), wenshi zhishi.

Fan Yu. (2004). Chinese Women and Family in Transformation time (Shehui zhuanxing zhong de zhongguo nüxing yu jiating) http://www.civillaw.com.cn. (Assessed 12 December, 2007)

Jiang Haixin (2005), Against myth and history: a new writing of motherhood in contemporary Chinese women's literature. New Zealand Journal of Asian Studies 7, 1(June): 93-111.

Jiang Zemin (1998), A discussion meeting with a new generation of leaders of National Federation of Women's Institutes and some women delegates to the Eighth National Congress. http://www.women.org.cn/allnews/110203/1.html (Assessed 21 Nov, 2007).

Kantorates (2008), Women, are they really liberated? http://www.cinespot.com/efeatures03.htm (Accessed 27 May 2008)

Kaplan, E. Ann, (1983), Women and Film: both sides of the camera. New York: Methuen.

1992. Motherhood and Representation: The Mother in Popular Culture and Melodrama. London: Routledge.

Li Lin (2006), Feminist Film since 1980s, Literature and Art Contending, No.4. (80 niandai yilai de nüxing dianying), wenyi zhengming.

Lu Hongshi, (2005), The History of Chinese Cinema 1905-1949: Narrative and Memory of Early Chinese Cinema, Culture and Art Publishing House. (Zhong guo dianying shi 1905-1949: zaoqi zhongguo dianying xushi he yiji), wenhua yishu chubanshe.

Rai, Shirin (1999), Gender in China, Ed. Robert Benewick \& Paul Wingrove, China in the 1990s, MacMillan. 
Rofel, Lisa (1999), Other Modernities: Gendered yearnings in China after socialism. University of California Press.

Thakur, Ravni (1997), Rewriting Gender: Reading contemporary Chinese women, London and New Jersey: Zed Books.

Wedellsborg, Wedell Ann (1999), Chinese Literature and Film in the 1990s, Ed. Robert Benewick \& Paul Wingrove. China in the 1990s, MacMilan.

Widmer,Ellen and Wang David Der-wei (1993), From May Fourth to June Fourth: fiction and film in twentieth-century China, Harvard University Press.

Wu Xiaoying (2005), The misuse of Women's body (nüxing de shenti hua jiqi lanyong) http://www.weekmag.info/html/93.htm (Accessed July 21, 2008)

Yin Hong \& Ling Yan (2002), A History Of Chinese Cinema: 1949-2000. Hu Nan Arts publisher. ( Hu Nan mei shu chu ban she).

Zhang Kangkang (1995), The Invisible Companion,(Yinxing banlü), Beijing Huayi Publisher.

Zhang Yingjin (2004), Chinese National Cinema. New York and London: Routledge.

Zhang Yingiin (2007), Rebel without a cause? China's new urban generation and postsocialist filmmaking, In Ed. Zhang Zhen, The Urban Generation: Chinese Cinema and Society at the turn of the twenty-first Century, Duke University Press. 